\title{
Thermal and Electrical Properties of Alumina/Graphene Mixtures in Polypropylene (PP) Matrix Based Composites
}

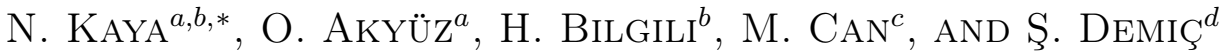 \\ ${ }^{a}$ Izmir Katip Celebi University, Department of Science Institute, Izmir, Cigli 35620, Turkey \\ ${ }^{b}$ Izmir Katip Celebi University, Central Research Laboratories, Izmir, Cigli 35620, Turkey \\ ${ }^{c}$ Izmir Katip Celebi University, Department of Material Science and Engineering, Izmir, Cigli 35620, Turkey \\ ${ }^{d}$ Izmir Katip Celebi University, Department of Engineering Science, Izmir, Cigli 35620, Turkey
}

\begin{abstract}
Thermal conductivity of polymers can be increased by loading high thermal conductive materials like ceramic, carbon and metal-based or its mixtures. In this study, high thermal conductive and electrically insulating composites were manufactured using alumina/graphene hybrid filler mixtures. Graphene content of the filler mixtures was prepared at $0,1,3,5$ and $7 \%$ of total filler amount and alumina/graphene combinations of fillers loaded polypropylene (PP) matrix composites prototypes were produced at 3:2 polymer/filler weight ratio by high speed thermo-kinetic mixer. Thermal and electrical behaviors of the composites were investigated by differential scanning calorimeter, simultaneous differential thermal analysis, thermal conductivity measurement equipment and electrical resistivity measurement equipment. It was observed that the crystallization temperatures of the composites increased with increasing amount of graphene in the composite. At the same time, it was observed that the thermal conductivity values started to rise after $5 \%$ of the initial drop by the increase of the amount of graphene in the composite. The thermal conductivity of the composites increased with the addition of graphene. No significant change in the electrical conductivities of the composite materials was observed.
\end{abstract}

DOI: 10.12693/APhysPolA.135.984

PACS/topics: DSC, SDT, thermal conductivity, composite, polypropylene (PP), graphene (G), alumina $\left(\mathrm{Al}_{2} \mathrm{O}_{3}\right)$

\section{Introduction}

$\mathrm{PP}$ is an important thermoplastic raw material for lots of industrial applications. It has good mechanical properties and impact resistivity. $\mathrm{PP}$ is a polyolefin group polymer that has general characteristics like thermally and electrically insulating behaviors [1]. Low thermal conductivity of PP restricts the application area of electronic packing industry. However, its electrical conductivity, low density and antistatic nature support the usage in microchips and processors interphase material. Some fillers and reinforcements such as carbon fiber $(\mathrm{CF})$, carbon black $(\mathrm{CB})$, graphene $(\mathrm{G})$, carbon nanotubes $(\mathrm{CNTs})$, ceramic and metal particles have been used to increase thermal conductivity, corrosion, strength, stiffness, abrasion resistance and other properties in polymer matrix based composites [2-5].

Alumina is a material with a thermal conductivity of $20 \mathrm{~W} / \mathrm{mK}$, electrical insulator and three dimensional ceramic base. Besides, the graphene is a carbon based material with high thermal and electrical conductivity and two dimensional planar structure. It is considered that both materials have different properties due to the fact that the thermal conductivity is high and structurally different from one another. However, the electrical

*corresponding author; e-mail: nnusrettersunn@gmail.com properties of the graphene cannot be used over a certain ratio because the electrical conductivity in the composite would increase.

In this study, thermal and electrical properties of alumina and graphene mixtures in PP were investigated by keeping the fill ratio constant. The filler/PP ratio was set at $40 \%$. The graphene percentage in the filler was determined to be $0 \%, 1 \%, 3 \%, 5 \%$ and $7 \%$. The study investigated the effect of two different filler materials of three dimensional (3D) and two dimensional (2D) structure on thermal properties and investigated its applicability in applications for electronic industry. It was aimed to investigate the effect of hybrid filler mixtures on the thermal conductivity of polymer-based composites. The change of thermal conductivity of the polyolefin derivatives of PP in the ceramic and carbon based hybrid filler system which added to matrix was observed.

\section{Experimental procedure}

PP was supplied from Petkim A.Ş. which was MH418 with UV protector added pellets. Its melting temperature was $168^{\circ} \mathrm{C}$ and melt flow index according to ASTM D1238 was between 4.0 to 6.0. The MH418 PP is suitable for melting in high speed thermo-kinetic mixer. Alumina was supplied from Morgan Technical Ceramics company which was $99.5 \%$ purity and under $20 \mu \mathrm{m}$ particle size. Graphene was supplied from GRAFEN Future Engineering. Graphene plaque thickness was $50 \mathrm{~nm}$ and surface dimension was $1.6 \mu \mathrm{m}$. Graphene plaques were 
suitable for mixing into polymer based materials. Before mixing PP, Alumina and graphene were dried at $80^{\circ} \mathrm{C}$ in drier oven for an hour. Neat PP and 0\% (Al-PP), 1\% (AlG1-PP), 3\% (AlG3-PP), 5\% (AlG5-PP) and 7\% (AlG7-PP) percentage of filler and $\mathrm{PP}$ were added to mixer chamber and mixed for almost one minute. Composite dough was pressed at 120 Psi for 3 min at heating side of the press and cooled at cooling side of the press for $1 \mathrm{~min}$.

Simultaneous differential thermal analysis (SDT) was conducted on a TA Instrument SDT Q600. The heating rate of samples was $10^{\circ} \mathrm{C} / \mathrm{min}$, and flow rate of nitrogen gas was $50 \mathrm{ml} / \mathrm{min}$. The temperature range of analyses was between ambient temperature to $600^{\circ} \mathrm{C}$. The weight and heat calibration of SDT was made before analysis. Measurements of crystallinity percentage, phase change temperatures and specific heat capacities of neat PP and composites were performed in a differential scanning calorimetry (DSC) instrument (TA Instrument, Q2000 model). Before measurements, DSC instrument was calibrated with certificated Indium standard. The measurement method was designed as heat/cool/heat procedure. Heating and cooling rate of samples were set up at $10^{\circ} \mathrm{C} / \mathrm{min}$ between to $20^{\circ} \mathrm{C}$ to $200^{\circ} \mathrm{C}$. At the end of the first heating cycle, $5 \mathrm{~min}$ isothermal step was applied in DSC oven for relaxation and removing all mechanical stress of the samples. Then samples were cooled to $20^{\circ} \mathrm{C}$. At the second heating cycle, again samples were started to heat $20^{\circ} \mathrm{C}$ to $200^{\circ} \mathrm{C}$ with the same heating rate and under $20 \mathrm{ml} / \mathrm{min}$ nitrogen atmosphere for preventing degradation and oxidation of samples. DSC thermogram of neat $\mathrm{PP}$ and composites were given at Fig. 1. Crystallinity enthalpy $\left(\Delta H_{c}\right)$, melting enthalpy $\left(\Delta H_{m}\right)$ and percentage of crystallinity (crys\%) of samples were evaluated from thermogram and crys $\%$ of PP matrix calculated by the Eq. (1). $\Delta H^{o}$ for PP was taken according to literature as $206.9 \mathrm{~J} / \mathrm{g}[6]$.

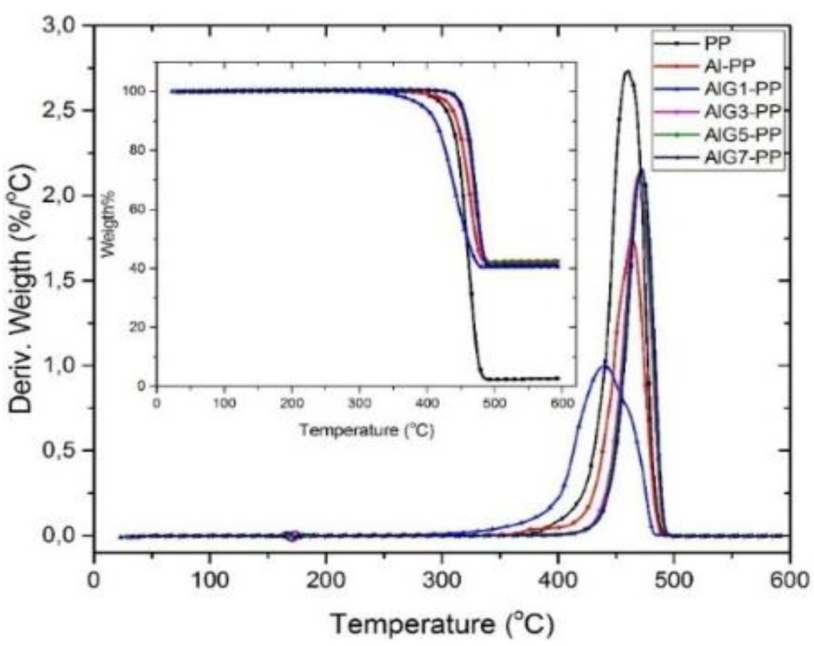

Fig. 1. Thermal decomposition thermogram of neat PP, Al-PP, AlG1-PP, AlG3-PP, AlG5-PP and AlG7-PP composites with differential thermal analysis.
The neat $\mathrm{PP}$ and composites thermal conductivities were measured by TC-i model thermal conductivity analyzer made by C-Therm. The test temperature of samples was at $25^{\circ} \mathrm{C}$ and the sensor capacity was between 0.1 to $4 \mathrm{~W} / \mathrm{mK}$. The thermal conductivity measurement technique was through plane direction. Electrical resistivity of composites and neat PP were measured by Keithley 8009 resistivity test fixture and Keithley 6517B electrometer. The electrical resistivity of all samples was measured and conductivity of samples was evaluated according to $1 / \rho \Omega \mathrm{m}^{-1}$ formula.

\section{Results and discussion}

According to Fig. 1, the composites thermal degradation temperature increases in addition of filler to PP matrix except AlG1-PP composite. At the thermogravimetric analysis thermogram, total residue of thermal degradation of composites was same and around $40 \%$. The differential thermal analysis results showed that thermal degradation rate of $\mathrm{PP}$ was higher than all composites but maximum thermal degradation temperature of composite shifted right side of thermogram which meant thermal stability increase.

Figure 2 showed that crystallinity temperature of composites increased by addition of filler into polymer matrix. The melting temperature of neat $\mathrm{PP}$ decreased with addition of alumina but graphene plaques addition to filler was increased melting temperature of hybrid filler loaded composites. Table I showed that crys\% of PP matrix increase by addition of graphene plaques, however, AlG1-PP composite crystallinity was higher than the other composites and neat PP.

$$
X_{c}[\%]=\frac{\Delta H_{m} / \varphi_{P P}}{\Delta H_{m}^{0}} \times 100 \% .
$$

Percentage of crystallinity crys $\%$ of PP was evaluated from formula $\Delta \mathrm{H}_{m}$ of PP.

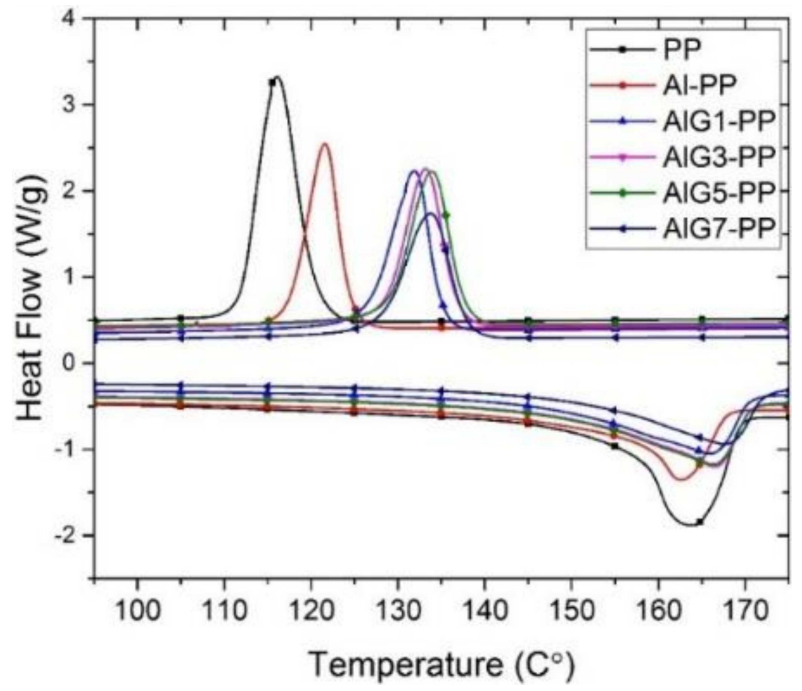

Fig. 2. Cooling and second heating cycles of DSC analysis thermogram of neat PP, Al-PP, AlG1-PP, AlG3-PP, AlG5-PP and AlG7-PP composites. 
TABLE I

Values of $\Delta \mathrm{H}_{c}, \Delta \mathrm{H}_{m}, \quad$ crys $\%$ of neat PP, Al-PP, AlG1-PP, AlG3-PP, AlG5-PP, and AlG7-PP.

\begin{tabular}{l|c|c|c}
\hline \hline & $\Delta \mathrm{H}_{c}[\mathrm{~J} / \mathrm{g}]$ & $\Delta \mathrm{H}_{m}[\mathrm{~J} / \mathrm{g}]$ & crys\% \\
\hline $\mathrm{PP}$ & 98.88 & 84.12 & 40.6 \\
Al-PP & 61.49 & 57.05 & 45.9 \\
AlG1-PP & 66.18 & 65.60 & 52.8 \\
AlG3-PP & 61.40 & 61.84 & 49.8 \\
AlG5-PP & 62.71 & 61.34 & 49.4 \\
AlG7-PP & 58.33 & 56.19 & 45.2
\end{tabular}

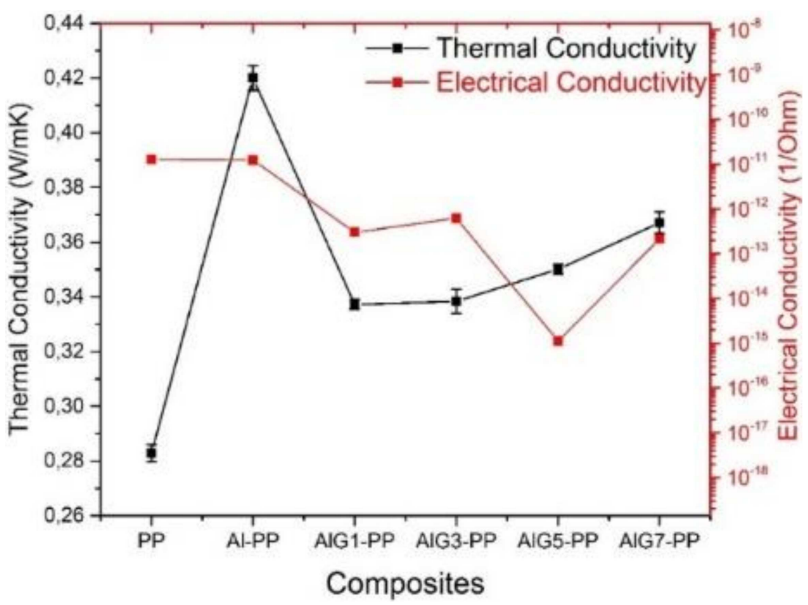

Fig. 3. Thermal and electrical conductivity measurements of neat PP, Al-PP, AlG1-PP, AlG3-PP, AlG5-PP, and AlG7-PP composites.

Figure 3 shows, that through plane thermal conductivity of composite decreased with the addition of graphene plaques, but, thermal conductivity started to rise with the increase in graphene ratio in the filler. The effect of $2 \mathrm{D}$ graphene plaques on the through plane thermal conductivity was negative for the enhancement of thermal conductivity of composites. At the same time, 3D alumina particles at through plane thermal conductivity decreased with the addition of graphene plaques into filler. Graphene plaques orientation in polymer matrix is parallel to through plane direction. Graphene plaques could be isolated from alumina particles. The graphene plaques added composites thermal conductivity may decrease with this mechanism.
It is known, that electrical conductivity of alumina and PP is very low, but graphene plaques electrical conductivity is dramatically high. In the literature, most of studies showed that polyolefin based polymers electrical conductivity could be observed with the addition of about $7 \%$ graphene plaques into the polymer matrix. In this study, composites graphene plaques to $\mathrm{PP}$ ratios were not reached with these values. Therefore, the electrical conductivity of composites surface did not change significantly.

\section{Conclusion}

The graphene plaques addition to alumina almost improved PP composites degradation temperature, thermal stability and crystallinity. However, through plane thermal conductivity was decreased by addition of graphene plaques. The in plane thermal conductivity measurement techniques could be tested for measuring 2D particle loaded polymer matrix based composites. Electrical conductivity of PP based composite surfaces was low and graphene plaques ratios were safe for electronic packing applications.

\section{References}

[1] L. Chen, H-F. Xu, S-J. He, Y-H. Du, N-J. Yu, $\mathrm{X}-\mathrm{Z}$. Du, J. Lin, S. Nazarenko, PLoS ONE 12, e0170523 (2017).

[2] E. Hammel, X. Tang, M. Trampert, T. Schmitt, K. Mauthner, A. Eder, P. Potschke, Carbon 42, 1153 (2004).

[3] T. Windhorst, G. Blount, Mater. Des. 18, 11 (1997).

[4] P.J.F. Harris, Int. Mater. Rev. 49, 31 (2004).

[5] A. Sommers, Q. Wang, X. Han, C. T'Joen, Y. Park, A. Jacobi, Appl. Thermal Eng. 30, 1277 (2010).

[6] C-M. Chan, J. Wu, J.-X. Li, Y.-K. Cheung, Polymer 43, 2981 (2002). 